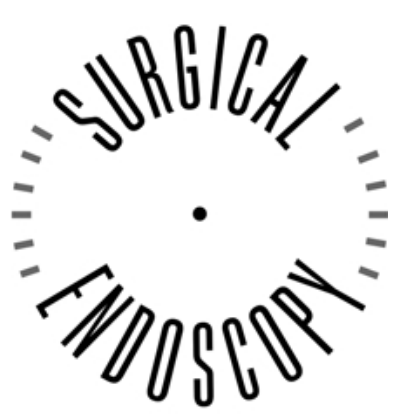

and Other Interventional Techniques

\title{
Robotic surgery training and performance
}

\section{Identifying objective variables for quantifying the extent of proficiency}

\author{
K. Narazaki, ${ }^{1}$ D. Oleynikov, ${ }^{2}$ N. Stergiou ${ }^{1}$ \\ ${ }^{1}$ University of Nebraska at Omaha, 6001 Dodge Street, Omaha, NE 68182, USA \\ ${ }^{2}$ University of Nebraska Medical Center, 983280 Nebraska Medical Center, Omaha, NE 68198-3280, USA
}

[Surg Endosc (2006) 20: 96-103, DOI: 10.1007/s000464-005-0095-8]

This article has been published online as DOI: 10.1007/s00464-005-3011-3. The publisher apologizes for any confusion. 